\title{
Atribuições de causas ao desemprego e valores pessoais
}

\author{
Sonia Maria Guedes Gondim \\ Universidade Federal da Bahia \\ José Luis Álvaro Estramiana \\ Universidad Complutense de Madrid \\ André de Figueiredo Luna \\ Thiago Santana Souza de Oliveira \\ Graceane Coelho de Souza \\ Universidade Federal da Bahia
}

\begin{abstract}
Resumo
O artigo explorou a associação entre atribuições de causas ao desemprego e valores pessoais. Participaram do estudo 205 pessoas empregadas e desempregadas. Utilizou-se uma escala de atribuição sobre as causas do desemprego baseada em Furnham (1982), o Perfil de Valores Pessoais (PVQ 21 - versão breve) de Schwartz incluído no European Social Survey (ESS) e um questionário sociodemográfico. Desempregados e empregados não diferem significativamente em relação às atribuições de causas do desemprego. Em relação aos valores, enquanto os desempregados apresentam valores de universalismo e benevolência, ligados à dimensão de autotranscedência, os trabalhadores empregados apresentam valores de segurança, ligados à dimensão de conservadorismo. Finalmente, encontrou-se uma associação significativa entre atribuições fatalistas e valores de tradição e segurança, entre atribuições sociais e valores de tradição, e entre atribuições individuais e valores de estimulação.
\end{abstract}

Palavras-chave: desemprego; emprego; atribuição; valores pessoais.

\begin{abstract}
Attributions of causes for unemployment and personal values. This article explored the association between explanations of unemployment and values. 205 people - employed and unemployed - were part of the study. Furnham's attribution scale on unemployment (1982) and a short version of Schwartz's. Portrait Value Questionnaire (PVQ 21) included in the European Social Survey (ESS), together with a social and demographic questionnaire were used. The conclusion was that employed and unemployed showed no differences in the attribution of causes for unemployment. In relation to values, unemployed showed differences in universalism and benevolence, linked to the domain of self-trascendence, whereas employed individuals had a greater attach to security values, linked to the domain of conservation. Finally, it was found a significant association between fatalistic attributions and security and tradition values, between tradition and social attributions and between stimulation and individualistic reasons for unemployment.
\end{abstract}

Keywords: unemployment; employment; attribution; personal values.

$\mathrm{O}$ desemprego pode ser definido como um problema crônico e estrutural das sociedades contemporâneas, sendo a causa de conflitos políticos e problemas sociais e psicológicos (Outhwaite \& Bottomore, 1996). São visíveis os efeitos de uma situação de desemprego para a pessoa, pois não se restringem somente à perda de rendimentos ou poder de consumo, mas também a várias outras esferas da vida pessoal (Alvaro-Estramiana, 1992). Analisar o desemprego, portanto, não pode excluir uma destas dimensões: a estrutural, a societal e a pessoal.

Se o trabalho remunerado é uma das atividades centrais da vida humana, sua escassez e redimensionamento tornam imprescindível a realização de estudos para compreender como as pessoas pensam, sentem e agem diante das novas e incertas exigências da sociedade. O emprego, uma das principais modalidades de trabalho remunerado da sociedade capitalista, ocupa um papel central na sobrevivência e no bem-estar do trabalhador. A sociedade salarial, todavia, tem passado por profundas mudanças na sua forma de organização. Desde a década de 1970, novas práticas produtivas foram definidas com impactos significativos sobre o trabalho (Pereira \& Brito, 2006). A flexibilidade foi uma das mudanças que tiveram inúmeras e indesejáveis consequências para as condições sociais e econômicas no mundo (Garrido, 2006; Giatti, Barreto, \& 
César, 2008).

Essas mudanças, entretanto, não aparecem como um fenômeno isolado e circunscrito a um país ou a uma região do mundo. Ao contrário, inserem-se num contexto de mudanças geopolíticas globais, em que as modalidades de emprego tradicionais têm sido substituídas pelas novas tecnologias, pela prestação de serviços terceirizados, acompanhando a emergência de novas formas de produção, organização e gestão (Tumolo, 1997). Se, de um lado, tais mudanças servem de mecanismos para a redução de custos, de outro, promovem alterações profundas nas formas contratuais de emprego e nas políticas de estabilidade e de promoção de carreira (Mattoso, 1999; Purcell, 2008).

Em resumo, as características mais marcantes da crise da sociedade salarial são a crescente precariedade das condições de trabalho, a instabilidade das ocupações, a expansão do setor informal, a individualização das relações de trabalho e a supressão de direitos dos trabalhadores. Ademais, dadas suas proporções atuais, o desemprego deixa de ser uma situação conjuntural provocada por crises econômicas para enraizar-se definitivamente na estrutura do mercado de trabalho mundial (Garrido, 2006).

No Brasil essas características não são diferentes. Desde a década de 1990, o desemprego no país sofreu mudanças significativas. $\mathrm{O}$ aumento da taxa de desemprego, todavia, afetou mais intensamente aos trabalhadores de baixa qualificação (Reis, 2006).

A Pesquisa Mensal de Emprego realizada na região Metropolitana de Salvador em maio de 2009 (Instituto Brasileiro de Geografia e Estatística [IBGE], 2009), onde foi realizada a pesquisa cujos resultados serão apresentados neste artigo, destacou que $35,1 \%$ dos desocupados (pessoas que não estão trabalhando, mas estão disponíveis para trabalhar) tinham entre 18 a 24 anos, e 52,5\% entre 25 a 49 anos. Em relação ao sexo, $59,2 \%$ eram mulheres. Do total de desocupados, $20,7 \%$ nunca trabalharam, e outros $24,2 \%$ eram os principais responsáveis pela família. Com relação ao tempo de procura, 40,2\% estavam em busca de trabalho por um período inferior a 30 dias e $40,1 \%$, por um período entre um e seis meses, destacando-se o fato de $56,7 \%$ terem 11 anos ou mais de estudo. Nesse mesmo período e ainda em relação à região metropolitana de Salvador, a proporção de pessoas desempregadas (que não tinham trabalho remunerado com vínculo contratual) em relação à população em idade economicamente ativa era de $21,7 \%$ (Departamento Intersindical de Estatística e Estudos Socioeconômicos [DIEESE], 2009). Em resumo, os dados sinalizam que o desemprego está afetando, principalmente, a mulher e o jovem.

Uma nova dicotomia se instala para além da divisão entre empregados e desempregados, trabalhadores qualificados e não qualificados, empregados permanentes e temporários, pois o mercado de trabalho da nova economia está dividido em uma mão de obra nuclear, formada por profissionais que lidam com a informação, e uma mão de obra descartável, que pode ser automatizada ou despedida segundo a demanda do trabalho e os custos envolvidos nessa contratação ou demissão (Garrido, 2006).

No bojo dessas transformações estruturais da sociedade e das relações de trabalho e emprego, emergem sentimentos de insegurança reforçados pela individualização no processo de construção e valorização das condições de empregabilidade de cada pessoa (Pereira \& Brito, 2006). Ao fazer isso, o discurso da empregabilidade transfere a responsabilidade da contratação para a pessoa (discurso da qualificação, capacitação e competências), desviando o foco de questões estruturais mais amplas que, muitas vezes, inviabilizam a inserção profissional no mercado de trabalho e enfraquecem as mobilizações coletivas, em favor da defesa da competitividade individual. Em outros termos, o desemprego passa a ser atribuído a uma inércia do indivíduo, que não se esforça para se tornar empregável em um mercado de trabalho cada vez mais ávido por perfis ajustados às suas demandas.

A crise do sistema financeiro norte-americano, desencadeada em 2008 e com repercussões mundiais para o emprego, fortalece o argumento de que o fenômeno do desemprego é um dos traços econômicos mais evidentes da sociedade contemporânea e que assume relevância crescente na vida de milhares de pessoas. Embora se reconheça que o problema do desemprego necessita ser analisado no nível macrossocial, pesquisar como empregados e desempregados atribuem as razões para o desemprego, e relacionar essas atribuições com o sistema de valores pessoais ajuda a compreender como os membros da sociedade avaliam e agem diante dessa grave questão social. Isso permitiria ter acesso a informações sobre os modos de enfrentamento dessa dura realidade a que todos estão sujeitos no mundo atual.

\section{Atribuições de causas do desemprego}

Uma das mais importantes premissas da abordagem da cognição social é a de que as pessoas agem como cientistas ingênuos, atribuindo explicações e razões para o que ocorre ao seu redor com a finalidade de dar sentido ao mundo em que vivem. Ao observarem as variações sistemáticas entre condições prévias e comportamentos subsequentes, dedicamse a fazer inferências sobre as causas dos acontecimentos (Augoustinos, Walker, \& Donaghue, 2006; Martinko, Douglas, $\&$ Harvey, 2006). Essas causas podem ser atribuídas ao próprio ator (personalidade, motivação, estados de humor, etc.) ou ao ambiente no qual se insere (fatores sociais, econômicos, acaso etc.) (Heider, 1958). Desde a abordagem da Psicologia do senso comum, que afirma que as pessoas agem como cientistas ingênuos, vários autores tentaram aperfeiçoar as teorias sobre como são atribuídas causas aos eventos do mundo (por exemplo, Jones \& Davis, 1965; Kelly, 1973; Weiner, 1986).

Mas qual seria a relevância de se estudar como as pessoas atribuem razões ao seu comportamento, aos demais atores com quem interagem e aos inúmeros eventos do mundo e do seu entorno? A justificativa é que a maneira como se age no mundo está relacionada ao modo como ele é pensado e valorado pelas pessoas.

Explicações são conceituadas como estados mentais individuais que dão fundamentos à intenção pessoal de agir (Crittiden, 1983; Malle, 2004). Estudar como as pessoas atribuem causas para o desemprego, uma grave questão social que tem assumido amplas proporções no mundo atual, ajuda a compreender como as pessoas individualmente lidam com esse problema e de que forma o tipo de explicação escolhida interfere 
na posição que assumem perante suas próprias condições de empregabilidade.

Ainda que muitos estudos sobre o desemprego tenham se preocupado em analisar as consequências psicológicas do desemprego sobre o bem-estar psicológico (Alvaro-Estramiana, 1992; Argolo \& Araújo, 2004; Borges \& Argolo, 2002; GarcíaRodríguez, 1993; Garrido, 1996; Jahoda, 1979; Warr, 1982), pesquisas realizadas nas décadas de 1980 e 1990 começam a preocupar-se por relacionar explicações do desemprego com diversas variáveis: estados afetivos depressivos (Feather \& Davenport, 1981), autoestima e lócus de controle (Hesketh, 1984), projeções futuras de situações de desemprego (Schaufeli, 1988), conseqüências psicológicas e comportamentais da perda do emprego (Prussia, Kinicki, \& Bracker, 1993) e atitudes e comportamentos de jovens na busca de trabalho (Furnham, 1984; Furnham \& Rawles, 1996).

Os resultados apontaram que pessoas altamente motivadas a buscar emprego tendem a se deprimir porque atribuem razões pessoais à falta de emprego; que a autoestima elevada e o lócus de controle interno estão associados a crenças de que a falha ou sucesso em conseguir emprego depende das habilidades pessoais; que a conquista do emprego enviesa a percepção que se tem da motivação inicial para encontrar trabalho; e que a atribuição interna e estável por estar desempregado influencia negativamente nas expectativas de se conseguir um novo trabalho.

Em estudo longitudinal, Gurney (1981) teve a oportunidade de acompanhar jovens recém-egressos da escola secundária. Uma de suas conclusões foi a de que a inserção dos jovens no mundo do trabalho fazia crescer a atribuição de causas internas para o fato de outros estarem desempregados. Ou seja, na medida em que deixava de ser um ator (desempregado) e passava a ser um observador (o desempregado era outra pessoa), o jovem tendia a atribuir responsabilidade pessoal ao desemprego, em detrimento das razões situacionais.

Ao analisar a atribuição de causas do desemprego no Reino Unido, Furnham (1982) concluiu que os empregados tendem a atribuir mais causas individuais ao desemprego que os próprios desempregados, os quais, por sua vez, tendem a atribuir causas societais para o mesmo problema. Esse resultado é semelhante ao encontrado por Gurney (1981). Confirmou-se sua hipótese de que as pessoas desempregadas por longo período de tempo estariam propensas a atribuir o desemprego a causas societais e fatalistas, enquanto as pessoas empregadas tendiam a atribuir a causas individuais. Outra hipótese de Furnham (1982) era a de que pessoas com nível de escolaridade mais alto tenderiam a atribuir causas societais para o desemprego, enquanto que pessoas com nível de escolaridade menor tenderiam a atribuir o mesmo problema a causas individuais. Os resultados indicaram que os empregados e todos aqueles de nível educacional mais baixo atribuíam maior importância às causas individuais para o desemprego que os desempregados e os de maior nível educacional, mas isso não se confirmou para todos os itens referentes a causas individuais inclusos no instrumento de pesquisa.

Duas conclusões podem ser extraídas desse resultado. A primeira é que, embora o aumento do nível educacional e instrucional leve as pessoas a serem mais críticas em relação à responsabilidade das instâncias governamentais e societais no desemprego, quando estão na condição de observadoras (empregadas), as pessoas ficam sujeitas ao viés atribuicional de que o ator (desempregado) tem alguma responsabilidade pessoal na condição desfavorável em que se encontra (Jones \& Davis, 1965). Um aspecto apontado por Schwartz (2006b) e que ajudaria a compreender esses resultados é que a hierarquia de valores pessoais sofre variação das circunstâncias de vida. Ou seja, o fato de se estar desempregado (ator) pode ativar valores gerando impactos na hierarquização, o que repercutiria na maneira como um evento é avaliado e se age em relação a ele.

A segunda conclusão é que o desemprego é um fenômeno complexo e tende a ser explicado de igual maneira, ou seja, mesclando-se causas individuais, societais e fatalistas. Essa conclusão está em conformidade com os resultados de estudo recente sobre atribuição de desemprego envolvendo oito países (Holanda, Grécia, Espanha, EUA, Polônia, Romênia, Reino Unido), em que o Brasil foi o único em que a solução tripartite não se confirmou (Mylonas et al., 2010).

\section{Discorrendo sobre valores na perspectiva de Schwartz}

As ações humanas estão, em última instância, apoiadas em valores, definidos como disposições psicológicas positivas dirigidas a metas que se situam tanto no plano concreto quanto no abstrato (Rokeach, 1981; Schwartz, 1994; Spranger, 1976). De caráter mais genérico que as atitudes, os valores ocupam uma posição central no sistema cognitivo da pessoa e têm como um dos seus objetivos principais o de orientar condutas no trabalho, no lazer, na ciência, na política, na moral, no direito, dentre tantas outras facetas da vida humana em sociedade (Krüger, 1995). Em síntese, a importância dos valores, em parte, decorre de seu caráter pragmático, de orientar ações, avaliar pessoas e explicar o mundo (Schwartz, 1992; 1994; 2006a; 2006b).

Os valores podem ser definidos como objetivos que os indivíduos perseguem, hierarquicamente ordenados de acordo com sua importância relativa aos demais valores (Schwartz, 1994). Tendo como base a perspectiva humanista de Maslow (1954), os valores podem ser concebidos como respostas dos indivíduos às necessidades biológicas, sociais e os requisitos para o bem-estar e a sobrevivência da coletividade (Bilsky, 2009). Os valores possuem as seguintes características, conforme Salanova, Gracia e Peiró (1996): (a) são aprendidos no processo de socialização; (b) diferem em intensidade e conteúdo de acordo com características pessoais e os grupos sociais de pertencimento; (c) determinam as escolhas ou decisões, bem como as reações emocionais consequentes; (d) ocupam uma posição central no sistema cognitivo em relação às atitudes e crenças; e, por último, (e) possuem caráter normativo, não se fixando a objetos e situações específicas. Portanto, os valores se relacionam com a história cultural, grupal e individual de cada pessoa (Ros, 2006; Schwartz, 2006a, 2006b).

A teoria transcultural desenvolvida por Schwartz (1994, 2006a, 2006b) propõe uma tipologia dos diferentes conteúdos dos valores, que já se encontra amplamente testada (Bilsky, 2009; Gouveia, Martínez, Meira, \& Milfont, 2001; Pasquali \& Alves, 2004; Schwartz, 1992; Tamayo, 2007; Tamayo \& 
Porto, 2009), e a partir da qual os valores representariam metas conscientes universais que permitiriam às sociedades atenderem, tanto às necessidades biológicas individuais, quanto aos princípios da ação social coordenada e grupal. Os valores estariam dispostos, de acordo com sua orientação (individual, coletiva ou mista), em duas dimensões bipolares: a primeira dimensão oscila entre valores de autopromoção (metas que atendem a interesses pessoais) e de autotranscendência (metas que visam à preservação do bem-estar coletivo e social). Os valores de autopromoção estão associados à motivação pelo poder, pela realização e pelas práticas hedonistas. Os valores de autotranscendência, ao contrário, relacionam-se às metas motivacionais apoiadas na benevolência e na preocupação com princípios universais de solidariedade, igualdade e justiça social.

A segunda dimensão marca a linha contínua que separa, de um lado, os valores de abertura à mudança, e, de outro, os de conservação. A autodeterminação, a estimulação e o hedonismo seriam considerados como metas motivacionais daqueles que valorizam a abertura à mudança, ao passo que a conformidade, a segurança e a tradição seriam as metas motivacionais dos que valorizam a conservação.

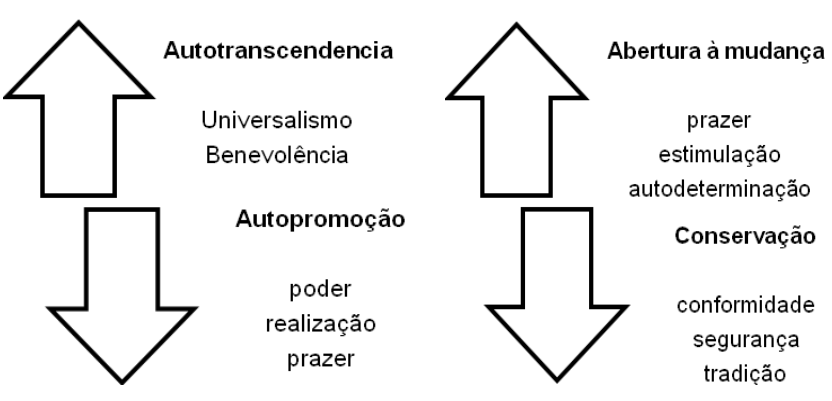

Figura 1: Representação das duas dimensões valorativas no modelo transcultural de Schwartz (1994)

Autodeterminação, estimulação, hedonismo, realização e poder social correspondem a valores que atendem mais aos interesses individuais, distinguindo-se da benevolência, tradição e conformidade, afins aos interesses coletivos. Universalismo e filantropia (ou benevolência) atenderiam tanto a interesses coletivos quanto individuais (Schwartz, 1994, 2006a, 2006b).

Embora se possa pensar no sistema de valores como uma estrutura relativamente estável - visto ser gradativamente constituído ao longo do tempo e vindo a ser o principal orientador de ações gerais em diversas esferas da vida pessoal, social, profissional, política e religiosa -, não se pode ignorar que ele é vulnerável a mudanças que ocorrem no meio circundante e que, direta ou indiretamente, afetam a vida de cada um (Schwartz, 2006a, 2006b). As características do processo de socialização de uma dada cultura também influenciam nessa estrutura. Em sua tentativa de caracterizar valores que seriam tipicamente da cultura brasileira, Tamayo (2007) encontrou em amostra de professores de ensino médio e estudantes universitários que o trabalho (dentre os quatro mencionados como típicos da cultura brasileira: trabalho, otimismo, vaidade e esperteza) ocupa o topo da hierarquia. Isso seria um indicador de que a realidade de um determinado contexto social pode ativar valores distintos de outras culturas, repercutindo na hierarquia e forçando a inclusão de valores que em outros contextos não seriam relevantes. $\mathrm{O}$ trabalho como valor na cultura brasileira também foi encontrado por Tinoco, Assencio, João e Claro (2010) em um estudo de caso relacionando valores e desempenho empresarial.

Ao admitir a plausibilidade dessas afirmativas, é possível supor também que as pessoas desempregadas tendem a atribuir maior importância ao valor de autotranscendência que pessoas empregadas. Essas últimas tenderiam a valorizar a abertura à mudança e à inovação, assim como à autopromoção. Seguindo essa lógica argumentativa, os desempregados estariam mais propensos que aqueles que se encontram empregados a perceber as injustiças na distribuição de recursos e oportunidades de inserção e crescimento profissional para todos os cidadãos, dando evidência aos valores de autotranscendência. Em contrapartida, os empregados passariam a valorizar aquilo que está em perfeita sintonia com o discurso contemporâneo de a empregabilidade ser de responsabilidade do trabalhador, e de que se deve lutar para ajustar as capacidades às novas demandas, garantindo, assim, espaço ocupacional.

Para concluir, ressalta-se que os valores, a condição de estar ou não empregado e as causas atribuídas para esse estado de coisas podem lançar luz à compreensão de como as pessoas avaliam sua inserção no mundo do trabalho, sua responsabilidade pessoal e das instâncias sociais nesse mesmo processo. A pesquisa aqui relatada tem como principal objetivo relacionar atribuições de causas de desemprego e valores de desempregados e empregados. A hipótese geral foi a de haver uma associação entre as atribuições de causas individuais (disposicionais, motivacionais), societais (governo, economia, etc.) e fatalistas (destino, ordem natural das coisas, etc.) do desemprego e os valores pessoais. Isso ajudaria a compreender quais valores estariam mais fortemente associados às atribuições sobre as causas do desemprego, e se a condição de empregado ou desempregado estaria associada a diferenças na hierarquia de valores pessoais. $\mathrm{O}$ interesse seria também o de comprovar se os empregados diferem dos empregados na maneira como explicam as causas de desemprego.

\section{Método}

O desenho do estudo foi planejado para investigar como empregados e desempregados atribuem causas ao desemprego e de que modo esses perfis atribuicionais (de acordo com as dimensões, individual, societal e fatalista) estão associados aos valores pessoais, conforme modelo teórico de Schwartz. Para esse fim, foram utilizados um questionário de causas de desemprego, baseado na pesquisa de Furnham (1982), e o Perfil de Valores Pessoais (PVQ 21 - versão breve) de Schwartz (1994) incluído no European Social Survey (ESS).

\section{Caracterização dos participantes}

Os desempregados que participaram da pesquisa eram usuários dos serviços do SINEBAHIA (Serviço Público de 
Intermediação para o Trabalho). Tal instituição é vinculada ao governo do Estado da Bahia e funciona como centro de recrutamento, seleção e treinamento de pessoas que buscam recolocação ou colocação no mercado de trabalho, e foi escolhido devido à concentração de pessoas em busca de emprego e à facilidade para aplicação dos questionários. Os participantes que diziam não ter vínculo empregatício e estarem procurando emprego eram convidados a responder o questionário nas próprias dependências do SINE. O grupo de empregados, por sua vez, foi recrutado em cursos de capacitação, pertencentes a diversas organizações da rede pública e privada.

Foram 205 participantes, sendo 101 empregados e 104 desempregados. Do total, $129(63,5 \%)$ eram mulheres e 74 $(36,5 \%)$ homens (duas pessoas não informaram o sexo). A idade variou de 18 a 60 anos $(M=29,96 ; D P=9,14) .104$ (52\%) possuíam até o ensino médio (até 12 anos de estudos), 34 (17\%) estavam cursando ensino superior e 62 (31\%) concluíram o ensino superior e alguns deles eram pós-graduados (cinco participantes não especificaram o nível educacional).

As mulheres representaram mais de $60 \%$ dos participantes (para empregados e desempregados). As diferenças aparecem na formação educacional, idade e situação familiar. Os desempregados possuíam nível educacional e instrucional mais baixo que os empregados. No primeiro grupo, $80,4 \%$ completaram somente o ensino médio, enquanto, no segundo grupo, $48 \%$ dos participantes concluíram o ensino superior. Os desempregados eram mais jovens $(M=27,64 ; D P=7,65)$ que os empregados $(M=32,33 ; D P=9,94)$, o que está em concordância com os dados do IBGE apresentados na seção anterior. A maioria dos desempregados era de solteiros $(71,6 \%)$ e uma parcela menor $(23,5 \%)$, casada.

Quanto ao tempo de desemprego, 52,2\% estavam na condição de desempregados entre um a seis meses e $23,9 \%$ há mais de 24 meses. Os demais entre sete a doze meses $(17,4 \%)$ e 13 a 24 meses (6,5\%). A maioria dos participantes do grupo de empregados encontrava-se inserida no setor privado $(59,4 \%)$, em contraposição ao setor público, que representou $38,6 \%$. Os 2\% restantes possuíam vínculo empregatício em ambos os setores. Em relação à jornada formal de trabalho, a média foi de 38,4 horas $(D P=8,89)$. Outra informação da amostra foi que $36,7 \%$ disseram raramente levarem trabalho para casa, enquanto $32,6 \%$ o fazem frequentemente ou sempre.

\section{Instrumentos}

O instrumento utilizado era composto pelo questionário de Atribuições de Causas de Desemprego, pelo PVQ21 e dados sociodemográficos. O questionário de atribuição de causas ao desemprego era composto de 19 itens, cobrindo as dimensões do modelo tripartite usado por Furnham (1982), a saber: causas individuais (7 itens), societais (6 itens) e fatalistas (6 itens). A versão brasileira foi obtida por um processo de tradução do instrumento original em inglês para o português, seguido de tradução reversa do português para o inglês. Cada item é uma sentença sobre uma causa de desemprego, de caráter individual, societal ou fatalista (por ex.: "Falta de esforço e preguiça das pessoas desempregadas"; "Sistema educacional não corresponde às demandas de trabalho do mercado atual", "Mudanças demográficas e populacionais”, respectivamente). Para responder aos itens, os participantes utilizaram uma escala de sete pontos variando de 1 (Muito Importante) a 7 (Nada Importante). Para fins de análise dos dados, os valores foram invertidos, o 1 correspondendo a nada importante e o 7 a muito importante.

O Perfil de Valores Pessoais de Schwartz (PVQ21) é composto de 21 itens, distribuídos em dez fatores que cobrem as motivações da teoria dos valores de Schwartz (1994, 2005, 2006a, 2006b). Os itens são apresentados sob a forma de breve descrição de uma pessoa à qual o participante deve se comparar e avaliar o quanto se parece com ele (Bilsky, 2009; Pasquali \& Alves, 2004). Cada sentença representa um valor (exemplo: "Aproveitar dos prazeres da vida é importante para ela. Ela gosta de se mimar") e sugere aspirações que implicitamente apontam para a importância de um perfil motivacional (Schwartz, 2005). Os participantes utilizaram uma escala de cinco pontos: 1 (Parece muito comigo), 2 (Parece comigo), 3 (Parece mais ou menos comigo), 4 (Parece pouco comigo), 5 (Não parece nada comigo). Para fins de análise de dados, os valores foram invertidos, sendo o 1 não parece nada comigo e o 5 parece muito comigo.

Por fim, constavam no questionário questões sociodemográficas: sexo, idade, nível educacional, estado civil e número de filhos. Quanto à condição ocupacional, perguntouse se a pessoa estava ou não empregada. Em caso de resposta negativa, o participante deveria informar o tempo em que estava desempregado.

\section{Resultados e discussão}

Esta seção será subdividida em três, visando a destacar os focos de análise: resultados gerais para atribuições de causas do desemprego, resultados gerais para valores e, por último, relações entre atribuições de causas e valores.

\section{Relações entre resultados gerais de causas de desem- prego e variáveis sociodemográficas}

$\mathrm{Na}$ tentativa de avaliar se as três dimensões do modelo de causas de desemprego (societais, individuais e fatalistas) usadas por Furnham (1982) se confirmavam na amostra, procedeu-se a aplicação do método de análise dos componentes principais, obtendo-se sete fatores. Em uma segunda tentativa, realizouse uma análise fatorial, com rotação varimax, forçando a distribuição em três fatores $(K M O=0,686)$, e o que se encontrou foi uma mescla de itens de razões individuais, societais e fatalistas em cada um deles, com cargas fatoriais variando de 0,35 a 0,68 (primeiro fator com 8 itens), 0,36 a 0,62 (segundo fator com 8 itens) e 0,58, a 0,77 (terceiro fator - com apenas 3 itens), os dois primeiros explicando $13 \%$ da variância, e o terceiro $9 \%$. Os resultados aqui encontrados fortalecem o que já foi apontado na literatura acerca da complexidade que envolve o processo de atribuição de causas de desemprego, evidenciando que as pessoas mesclam explicações individuais, societais e fatalistas.

Acredita-se que uma das explicações possíveis é a das especificidades culturais, pois independentemente de se estar desempregado e empregado, de ser do sexo masculino ou feminino, de se perceber como ator ou observador do desemprego e do nível educacional, o brasileiro avalia o desemprego como 
um fenômeno multicausal.

Mas, apesar de reconhecer essa imprecisão do modelo tripartite, decidiu-se tratar o banco de dados agrupando os itens fatalistas, societais e individuais (criando um escore geral para cada um deles), para fins de análises subsequentes, visando a proceder a correlações com a variável dos valores pessoais, sem deixar de considerar criticamente as implicações dessa decisão.

Os resultados da amostra total (empregados e desempregados) indicam não haver diferenças significativas na atribuição de causas de desemprego em relação às razões individuais $(M=$ $5,71 ; D P=0,56)$, societais $(M=6,08 ; D P=0,49)$ e fatalistas $(M$ $=5,57 ; D P=0,57)$, o que fortalece o argumento de que brasileiros acreditam que o desemprego é decorrente de múltiplos fatores.

$\mathrm{O}$ teste- $t$ (student de amostras independentes) não revelou diferenças significativas $(p>0,05)$ nas médias entre participantes empregados e desempregados em relação à atribuição de causas de desemprego $\left(t_{(201)}=1,74, p>0,05, t_{(201)}=1,00, p>0,05, t_{(199)}\right.$ $=1,55, p>0,05)$, assim como também não houve diferença entre $\operatorname{sexos}\left(t_{(199)}=0,53, p>0,05, t_{(199)}=0,88, p>0,05, t_{(199)}\right.$ $=1,30, p>0,05)$, respectivamente para causas individuais, societais e fatalistas. As análises de variância (ANOVA one way) evidenciaram diferenças significativas entre explicações individualistas e fatalistas para o desemprego e o nível educacional $F_{(2,197)}=5,91, p<0,05$ e $F_{(2,197)}=4,33, p<0,05$. A análise post hoc utilizando o teste de Tukey evidencia que as médias das explicações individuais dos participantes de ensino superior (ou com pós-graduação) $(M=5,55,95 \%$ CI $[5,41$, $5,68])$ são significativamente menores que as dos participantes de ensino médio $(M=5,84,95 \%$ CI $[5,74,5,95)] p<0,05$, assim como as médias das explicações fatalistas dos participantes de ensino superior (ou com pós-graduação) $(M=5,41,95 \% \mathrm{CI}$ $[5,27,5,56])$ também foram menores que as dos participantes de ensino médio ( $M=5,68,95 \%$ CI $[5,57,5,79]) p<0,05$.

Os dados confirmam parcialmente os resultados do estudo de Furnham, visto que embora a amostra desse estudo não tenha apresentado diferenças nas médias de explicações societais entre grupos educacionais distintos, no que tange às explicações individuais e fatalistas as pessoas de nível médio apresentam escores mais altos que as de nível de ensino superior, o que coincide com os dados de Furnham.

\section{Relações significativas entre resultados gerais de va- lores pessoais e variáveis sociodemográficas}

Dentre as dimensões do PVQ-21 (vide Figura 1), os participantes desempregados $(M=2,31, D P=1,25 ; M=2,83$, $D P=1,33 ; M=2,60, D P=1,24$, respectivamente) e empregados $(M=2,17, D P=0,86 ; M=2,64, D P=1,20 ; M=2,68, D P=$ 1,00 , respectivamente) apresentaram diferenças significativas por meio do teste $\mathrm{t}$ (student de amostras independentes) quanto ao Universalismo $t_{(203)}=0,93, p<0,001$, Benevolência (filantropia) $t_{(203)}=1,10, p<0,05$ e Segurança $t_{(203)}=0,53, p<0,05$.

Universalismo corresponde à compreensão e apreço pelo bem-estar de todos e da natureza; de forma semelhante, a benevolência está relacionada a um cuidado pelo bem-estar das pessoas com as quais se convive. A ênfase compartilhada dos dois valores se refere justamente ao bem-estar alheio e à superação dos interesses egoístas. A segurança, por sua vez, diz respeito à valorização da estabilidade de si mesmo, das relações e da sociedade como um todo (Schwartz, 1994; Tamayo \& Porto, 2009).

Os resultados sinalizam, então, que os desempregados apresentam médias mais elevadas que os empregados em relação ao universalismo e à benevolência, enquanto os empregados apresentam escores um pouco mais elevados de segurança. Destarte, os desempregados da amostra estariam mais sensíveis ao bem-estar geral e à busca do bem comum, enquanto os empregados estariam mais preocupados com questões de segurança. Muito provavelmente, isso se relaciona com a preocupação de não perder a condição de relativa estabilidade em que o empregado supõe estar.

A análise de variância (ANOVA one way) não evidenciou diferenças significativas nos escores dos dez tipos motivacionais de valores (universalismo, benevolência, tradição, conformidade, poder, êxito, hedonismo, estimulação, autodireção) e o nível educacional. Uma explicação possível pode ser a de que a condição de estar ou não empregado (status ocupacional) ativa valores e repercute na hierarquia, não acontecendo o mesmo com o nível educacional. Ou seja, a construção de valores se dá ao longo do processo de socialização, não se restringindo à educação formal; ademais, a ativação de valores parece estar mais ligada às experiências de vida que ao nível educacional.

Associando atribuição de causas ao desemprego e valores para empregados e desempregados

Ao realizar uma análise de correlação entre as causas atribuídas ao desemprego e as dimensões de valores do PVQ21, foram encontradas algumas correlações com significância estatística. Observou-se, então, que as causas fatalistas (início da automação em larga escala, mudança demográfica e populacional, incorporação de novas tecnologias pelas empresas, fusão de empresas) apresentam correlação positiva tanto com o tipo motivacional de tradição $(r=0,16, p<0,001)$ quanto com o tipo motivacional de segurança $(r=0,19, p<0,001)$, ou seja, com a dimensão de valor conservação.

Pelo que se observa do significado do valor conservação (em que se encontram a tradição e a segurança), e os itens de razões fatalistas que constam no instrumento, depreende-se que a crença de que "as coisas são como são", expressa uma tendência de perceber os eventos sociais, tais como o desemprego, como algo inevitável, do qual não se tem controle, estando associado aos valores de conservação. Em outras palavras, as pessoas que têm valores de conservação tendem a acreditar que os problemas sociais, tais como o desemprego, decorrem de processos inevitáveis de desenvolvimento.

Há de se considerar, no entanto, que o tipo motivacional tradição também obteve correlação positiva com as causas societais $(r=0,22, p<0,001)$, o que pode indicar a complexidade do processo atribuicional sobre o desemprego e sua relação com o sistema de valores pessoais. As razões societais expressam a crença de que as instâncias governamentais não se mostram competentes para lidar com os problemas do desemprego e não adotam políticas que asseguram o emprego no país. Em acréscimo a isso, o sistema educacional se revela pobre e não atende às demandas do mercado de trabalho atual, não 
preparando as pessoas para estarem aptas e qualificadas para o trabalho.

Encontrou-se também uma correlação positiva entre o tipo motivacional de estimulação e causas individuais $(r=0,16, p<$ $0,05)$. A estimulação está relacionada com o valor de abertura a novas experiências e a inovação, fazendo contraponto à tendência valorativa do conservadorismo. Com base nas sentenças do questionário de atribuição de causas individuais do desemprego, o desempregado é percebido como pouco inteligente e esforçado, preguiçoso, não manifesta vontade para ajustar-se às demandas de trabalho e não possui autoconhecimento sobre suas reais qualificações que o fariam buscar alternativas para se capacitar melhor para o mercado. Além disso, é orgulhoso para aceitar trabalhos menos qualificados para assegurar emprego.

A correlação entre estimulação e causas individuais sugere, então, que quem valoriza a inovação acredita que o desempregado não se esforçou o suficiente para conseguir emprego. Supostamente, há uma crença incorporada do discurso da empregabilidade, ou seja, de que a condição de emprego depende de um esforço pessoal para buscar a inovação (Pereira $\&$ Brito, 2006).

\section{Considerações finais}

O que se pode concluir sobre empregados e desempregados e as relações entre causas de desemprego e hierarquia de valores?

A primeira conclusão é da ausência de diferenças na atribuição de importância às causas sociais, individuais e fatalistas sobre o desemprego. Empregados e desempregados do estudo atribuíram a todas elas um elevado grau de importância, sem distinção significativa entre um ou outro tipo de explicação.

A segunda conclusão é que a condição ocupacional e o sexo não interferem na atribuição de causas para o desemprego. Independentemente de serem empregados ou desempregados, homens ou mulheres, os brasileiros que participaram desse estudo creem que as explicações para o desemprego estão relacionadas a múltiplos fatores (individuais, societais e fatalistas), visto não terem sido encontradas diferenças significativas entre esses grupos em relação aos três tipos de atribuições de causa de desemprego. No que tange ao nível educacional, contudo, foram encontradas diferenças significativas para as explicações individualistas e fatalistas do desemprego. Pessoas de nível de ensino superior (ou pós-graduação) tendem a atribuir menos causas individuais e fatalistas ao desemprego que as pessoas de nível de ensino médio.

A terceira conclusão é que os desempregados e empregados adotam valores distintos. Os primeiros se mostram mais sensíveis ao bem-estar geral e à busca do bem comum (universalismo e benevolência), enquanto os empregados se preocupam mais com questões de segurança (dimensão conservadora). A hipótese é que isso esteja relacionado com a preocupação de não perder a condição de relativa estabilidade em que esse último grupo (empregados) se encontra.

A quarta e última conclusão é sobre as relações entre a atribuição de causas de desemprego e hierarquia de valores pessoais. As causas fatalistas e societais apresentam correlação positiva com os valores da dimensão de conservadorismo. Isso permite concluir que as pessoas que se posicionam mais próximas da dimensão valorativa do conservadorismo, em contraposição às que valoram a abertura para a mudança, tendem a acreditar que os problemas sociais são decorrentes tanto da inevitabilidade do processo de desenvolvimento da sociedade, quanto de políticas públicas inadequadas.

Essa ambígua conclusão fortalece o argumento de que o processo de atribuição de causas ao desemprego é mais complexo e não se ajusta perfeitamente a um modelo tripartite que agrupa fatores distintos, sinalizando que no caso dessa amostra de brasileiros (com predomínio de pessoas de nível médio e superior), tais causas não se comportaram de modo independente. Assinala-se, todavia, que a dimensão de abertura à mudança, mostrou-se associada à atribuição de causas individuais, revelando que, de algum modo, está sendo incorporado o discurso amplamente difundido da co-responsabilidade do trabalhador na sua inserção profissional.

Um dos aspectos críticos da pesquisa se refere à amostra de desempregados. Não se tem segurança de que o perfil de desempregados que utiliza os serviços do SINE represente o perfil do desempregado brasileiro, embora sejam corroborados pelos indicadores do IBGE. A dúvida deriva da constatação de uma elevada incidência de desempregados com até seis meses nessa condição, o que pode ser um sinal de que, após esse período, as pessoas que estão ativamente em busca de emprego e fazem uso dos serviços do SINE podem ter perdido a confiança de que conseguirão recolocar-se no mercado e, portanto, deixam de usar esse serviço de utilidade pública.

Para finalizar, reconhecem-se os limites deste estudo, alguns já enumerados no corpo do texto, mas considera-se que os resultados apontam caminhos que precisam ser mais bem explorados em pesquisas futuras, como a redefinição do modelo teórico de atribuição de causas ao desemprego e a mediação do status ocupacional (empregado e desempregado) no padrão de atribuição de causas do desemprego e na hierarquia de valores pessoais.

\section{Referências}

Alvaro-Estramiana, J. L. (1992). Desempleo y bienestar psicológico. Madrid: Siglo Veinteuno de España.

Argolo, J. C. T., \& Araújo, M. A. D. (2004). O impacto do desemprego sobre o bem-estar psicológico dos trabalhadores da cidade de Natal. Revista de Administração Contemporânea, 8(4), 161-182.

Augoustinos, M., Walker, I., \& Donaghue, N. (2006). Social cognition: an integrated introduction. London: Sage Publications.

Bilsky, W. (2009). A estrutura de valores: sua estabilidade para além de instrumentos, teorias, idade e culturas. Revista de Administração Mackenzie, $10(3), 12-33$

Borges, L. O., \& Argolo, J. C. T. (2002). Adaptação e validação de uma escala de bem-estar psicológico para uso em estudos ocupacionais [Versão eletrônica]. Avaliação Psicológica, 1(1), 17-27.

Crittiden, K. S. (1983). Sociological aspects of attribution. Annual Review of Sociology, 9, 425-446.

Departamento Intersindical de Estatística e Estudos Socioeconômicos (DIEESE). (2009). PED - Região Metropolitana de Salvador - Maio de 2009. Recuperado de http://www.dieese.org.br/ped/ssa/pedssa0509.pdf 
Feather, N. T., \& Davenport, P. R. (1981). Unemployment and depressive affect: a motivational and attributional analysis. Journal of Personality and Social Psychology, 41(3), 422-436.

Furnham, A. (1982). Explanations for unemployment in Britain. European Journal of Social Psychology, 12, 335-352.

Furnham, A. (1984). Getting a job: school-leavers' perception of employment prospects. British Journal of Educational Psychology, 54, 293-305.

Furnham, A., \& Rawles, R. (1996). Job search strategies, attitudes to school and attribution about unemployment. Journal of Adolescence, 19, 355-369.

García-Rodríguez, Y. (1993). Desempleo: alteraciones psicológicas.Valencia: Promolibro.

Garrido, A. (1996). Psicología social del desempleo. In J. L. Alvaro, A. Garrido, \& J. R. Torregrosa (Orgs.), Psicología social aplicada (pp. 122-152). Madrid: McGraw-Hill.

Garrido, A. (2006). Sociologia del trabajo. Barcelona: Universitat Oberta de Catalunya.

Giatti, L., Barreto, S. M., \& César, C. C. (2008). Informal work, unemployment and health in Brazilian metropolitan areas, 1998 and 2003. Cadernos de Saúde Pública, 24(10), 2396-2406.

Gouveia, V. V., Martinez, E., Meira, M., \& Milfont, T. L. (2001). A estrutura e o conteúdo universais dos valores humanos: análise fatorial confirmatória da tipologia de Schwartz. Estudos de Psicologia (Natal), 6(2), 133-142.

Gurney, R. M. (1981). Leaving school, facing unemployment, and making attributions about the causes of unemployment. Journal of Vocational Behavior, 18(1), 79-91

Heider, F. (1958). The psychology of interpersonal relations. New York: Wiley.

Hesketh, B. (1984). Attribution theory and unemployment: Kelley's covariation model, self-esteem, and locus of control. Journal of Vocacional Behavior, 24, 94-109.

Instituto Brasileiro de Geografia e Estatística. (2009). Pesquisa Mensal de Emprego. Recuperado de http://www.ibge.gov.br/home/estatistica/ indicadores/trabalhoerendimento/pme_nova/pme_200905bacomentarios.pdf

Jahoda, M. (1979). The impact of unemployment in the 1930`s and the 1970 `s. Bulletin of British Psychological Society, 32, 309-314.

Jones, E. E., \& Davis, K. E. (1965). From acts to dispositions: the attribution process in person perception. In L. Berkowitz (Org.), Advances in experimental social psychology (Vol. 2, pp. 219-266). New York: Academic Press.

Kelly, H. H. (1973). The processes of causal attribution process. American Psychologist, 28, 107-128.

Krüger, H. R. (1995). Psicologia das crenças: perspectivas teóricas (Tese para Professor Titular, Universidade Estadual do Rio de Janeiro, Rio de Janeiro).

Malle, B. F. (2004). How the mind explains behavior. Cambridge: Bradford Book, MIT Press.

Martinko, M. J., Douglas, S. C., \& Harvey, P. (2006). Attribution theory in industrial and organizational psychology: a review. In G. P. Hodgkinson, \& J. Kevin Ford (Orgs.), International Review of Industrial and Organizational Psychology (Vol. 21, pp. 127-188). Chichester: John Wiley \& Sons.

Maslow, A. H. (1954). Motivation and personality. New York: Harper.

Mattoso, J. O. (1999). Brasil desempregado: como foram destruidos mais de 3 milhões de empregos nos anos 90 ( $2^{\underline{a}}$ ed.). São Paulo: Fundação Perseu Abramo.

Mylonas, K., Furnham, A., Konstantinidis, E., Papazoglou, S., Divale, W., Leblebici, C., ... Boski, P. (2010, julho). The explanations of unemployment scale: an eight-country study on factor equivalence. Comunicação apresentada no XX Congress of the International Association for Cross Cultural Psychology, Melbourne.

Outhwaite,W., \& Bottomore, T. (Orgs.) (1996). Dicionário do pensamento social do século $X X$. Rio de Janeiro: Jorge Zahar.

Pasquali, L., \& Alves, A. R. (2004). Validação do Portraits Questionnaire - PQ de Schwartz para o Brasil [Versão Eletrônica]. Avaliação Psicológica, 13(2), 73-82.

Pereira, M. C., \& Brito, M. J. (2006). Desemprego e subjetividade no contexto brasileiro: uma análise interpretativa sob a ótica dos excluídos do mercado de trabalho industrial. Revista Mal-estar e Subjetividade, 1(1), 143-181.

Prussia, G. E., Kinicki, A. J., \& Bracker, J. S. (1993). Psychological and behavioral consequences of job loss: a covariance structure analysis using Weiner's (1985) attribution theories. Journal of Applied Psychology, 78(3), 382-394.

Purcell, K. (2008). Fragmentação ocupacional, trabalho flexível e forças de trabalho segmentadas. In N. A. Guimarães, A. Cardoso, P. Elias, \& K. Purcell (Orgs.), Mercado de trabalho e oportunidades: reestruturação econômica, mudança ocupacional e desigualdade na Inglaterra e Brasil (pp. 77-120). Rio de Janeiro: Fundação Getúlio Vargas.

Reis, M. (2006). Os impactos das mudanças na demanda por trabalho qualificado sobre o desemprego por nível de qualificação durante os anos noventa no Brasil. Revista Brasileira de Economia, 60(3), 297-319.

Rokeach, M. (1981). Crenças, atitudes e valores. Rio de Janeiro: Interciência.

Ros, M. (2006). Valores, atitudes e comportamento: uma nova visita a um tema clássico. In M. Ros, \& V.V. Gouveia (Orgs.), Psicologia social dos valores humanos: desenvolvimentos teóricos, metodológicos e aplicados (pp. 87114). São Paulo: Senac.

Salanova, M., Gracia, F. J., \& Peiró, J. M. (1996). Significado del trabajo y valores laborales. In J. M Pieró, \& F. Prieto (Orgs.), Tratado de psicología del trabajo (pp. 35-63). Madri: Sintesis Psicología.

Schaufeli, W. B. (1988). Perceiving the causes of unemployment an evaluation of the causal dimension scale in real-life-situation. Journal of Personality and Social Psychology, 54(2), 347-356.

Schwartz, S. H. (1992). Universals in the content and structure of values: theoretical advances and empirical tests in 20 countries. In M. Zanna (Org.), Advances in experimental social psychology (Vol. 25, pp. 1-64). San Diego: Academic Press.

Schwartz, S. H. (1994). Are there universal aspects in the structure and contents of human values? Journal of Social Issues, 50(4), 19-45.

Schwartz, S. H. (2005). Validade e aplicabilidade da teoria de valores. In A. Tamayo, \& J. B. Porto (Orgs.), Valores e comportamentos nas organizações (pp. 56-95). Petrópolis: Vozes.

Schwartz, S. H. (2006a). Há aspectos universais na estrutura e no conteúdo dos valores humanos? In M. Ros, \& V.V. Gouveia (Orgs.), Psicologia social dos valores humanos: desenvolvimentos teóricos, metodológicos e aplicados (pp. 55-85). São Paulo: Senac.

Schwartz, S. H. (2006b). Basic human values: an overview. Recuperado de http://www.yourmorals.org/schwartz.2006.basic\%20human\%20values.pdf

Spranger, E. (1976). Formas de vida: Psicologia entendida como ciência do espírito e ética da personalidade. Rio de Janeiro: Zahar.

Tamayo, A. (2007). Hierarquia de valores transculturais e brasileiros. Psicologia: Teoria e Pesquisa, 23(especial), 7-15.

Tamayo, A., \& Porto, J. B. (2009). Validação do Questionário de Perfis de Valores (QPV) no Brasil. Psicologia: Teoria e Pesquisa, 25(3), 369-376.

Tinoco, J. E. P., Assencio, E. W., João, B. N., \& Claro, J. A. C. (2010). Influência dos valores individuais no desempenho empresarial: um estudo usando o inventário de valores de Schwartz. XIII Semead - Seminários em Administração. Texto completo. Recuperado de http://www.ead.fea.usp.br/ semead/13semead/resultado/trabalhosPDF/456.pdf

Tumolo, P. S. (1997). Metamorfoses no mundo do trabalho: revisão de algumas linhas de análise. Educação \& Sociedade, 18(59), 333-350.

Warr, P. (1982). Psychological aspects of employment and unemployment. Psychological Medicine, 12, 7-11.

Weiner, B. (1986). An attribution theory of motivation and emotion. New York: Spring-Verlag. 
Sonia Maria Guedes Gondim, doutora em Psicologia Social pela Universidade Federal do Rio de Janeiro, é professora associada da Universidade Federal da Bahia. Endereço para correspondência: Rua Rodrigo Argolo, 293, $\mathrm{Apt}^{\mathrm{O}} 502$ - Rio Vermelho

CEP: 41940220. Salvador-BA. E-mail: sggondim@ufba.br

José Luis Álvaro Estramiana, doutor Psicologia Social pela Universidad Complutense de Madrid, é professor catedrático de Psicologia Social na mesma universidade. E-mail: jlalvaro@cps.ucm.es

André de Figueiredo Luna, graduando em Psicologia na Universidade Federal da Bahia, é bolsista de Iniciação Científica do CNPq. E-mail: andre_luna_@hotmail.com

Thiago Santana Souza de Oliveira, graduando em Psicologia na Universidade Federal da Bahia, é bolsista de Iniciação Científica do CNPq. E-mail: thg.souzaoliveira@gmail.com

Graceane Coelho de Souza, psicóloga, bolsista PIBIC/FAPESB (2008-2009) na Universidade Federal da Bahia. E-mail: grace.souza@gmail.com 